\title{
The Development Technologies of Double Layer Suppositories on the Basis of Licorice Extract and Paracetamol
}

\author{
Abdrakhmanova Gulmira Marsovna ${ }^{1}$, Zhaugasheva Sabira Kedelevna ${ }^{1}$ and Pavelkovskaya Galina Petrovna ${ }^{2}$ \\ 1. Department of Pharmacology, Karaganda State Medical University, Karaganda 100008, Kazakhstan \\ 2. Department of Pharmacology, Almaty State Institute of Postgraduate Medical, Almaty 050016, Kazakhstan
}

\begin{abstract}
Abctract: This work presents the results of research on the development of technologies bilayer suppositories new drug of combined action with the use of a thick extract of licorice and paracetamol. The optimal composition with use of hydrophobic and hydrophilic bases for double layer suppositories is selected. Suppositories are produced by pouring in split form. Given that carbon dioxide content of the extract was $5.0 \%$ by weight of the suppository, rational methods should be considered as a preliminary preparation of the concentrate. By dissolving the active ingredients in the part of molten basis. To assess the quality of the dosage form the investigation in accordance with the Pharmacopoeia Kazakhstan were performed. In operation conducted structural and mechanical properties rectal dosage forms which have a significant influence on their consumers, biopharmaceutical characteristics and play a determining role in the selection process parameters dosing suppository mass, speed and mixing time in the manufacturing process. The main physical and chemical indicators, and their standardization was done. Bilayer suppositories are smooth uniform surface, torpedo shape, oily to the touch. The double layer suppositories obtained in the longitudinal section of the outer layer visible brownish - yellow color and an inner layer of white color with a cream shade. The advantage of the developed dosage form as opposed to the analogue is the ability to use two kinds of actions - it is carbon dioxide extract of licorice and paracetamol, which will provide a wide range of pharmacological activity on the body and will demonstrate the combined effect.
\end{abstract}

Key words: Licorice extract, double layer suppositories, paracetamol, standardization.

\section{Introduction}

There are the sources of raw materials of pharmacopeial types in the Central and South Kazakhstan. The variety of biological active combinations being a part of licorice determines its wide spectrum of pharmacological activity: anti-inflammatory, antiulcerous, antiviral, immunomodule, hypoglycemic and cardioprotectory [1-5]. At present from the licorice root is extracted and described in the scientific literature more than 50 triterpenoids, 200 individual phenol connections, amino acids, polysaccharides and lipids [6-7]. The pharmacopeial preparations: licorice syrup, dry licorice

Corresponding author: Abdrakhmanova G. M., master's degree, research fields: technology of medicines, pharmacology. E-mail: Gulmira-abdrakhmanova@mail.ru. extract, thick licorice extract are used in medical practice [8].

The investigations as a plan of broadening the variety of medicinal forms on the basis of root licorice extract are of special actuality. Due to the whole spectra of merits of the rectal method use the preparations, its form and content are improved.

The double layer rectal suppositories with the use of root licorice extract and paracetamol of combined action were developed, the main physico-chemical, reological findings and their standardization were done.

\section{Materials and Mehtods}

As the acting substances in suppositories paracetamol is taken (internal layer), allowing to get the antipyretic effect and root licorice extract (external 
layer), giving the antiviral action and also the accelerating process of the tissue epithelization. In all 10 compounds on hydrophilic and hydrophobic basis were prepared. The suppositories were made by the method of pouring out in detachable forms. As the hydrophobic bases vitepsol W 35, vitepsol H 15, lasupol, surface active substances in various concentration, hard fat, emulsifier $\mathrm{T}_{2}$, cocoa oil and distilled monoglycerides were used. As the hydrophilic basis the mixtures of polyethylenglycol 400, polyethylenglycol 1500 , polyethylenglycol 4000 were taken. The suppositories were received by the common mass within 3.8-4.1. Inside of each nest the metal shaft greased by the soap spirit was placed. After cooling the shaft was removed and the fused and slightly cooled compound was filled in with paracetamol. The forms were placed in refrigerator.

\section{Results and Discussions}

For the development of the optimal suppositories technology it was necessary to study the influence of some technological factors on the quality of the developed medicinal form: temperature regimen at the stage of suppository mass preparation and its pouring out in cell packing; speed and duration of homogenization of components and to determine experimentally the expense coefficients and carry out the necessary technological calculations.

Taking into account that the content of carbonic acid extract composes $5.0 \%$ from the mass of suppository, the rational way is considered to be the preliminary preparation of the concentrate dissolving the acting substances in the part of the fused basis.

For this the calculated on series of preparation the quantity of hard fat was put in reactor with steam-boiler jacket, adding the grinded cocoa oil and these components were melted in $\mathrm{t}^{0} 60,70,80{ }^{\circ} \mathrm{C}$ mixing by the impeller mixer with the rotation rates $30,60,120$ and $150 \mathrm{~min}^{-1}$. The process completion was decided due to the absence of visible particles in fusion.

In received suppositories on the longitudinal incision the external and internal layers were seen. The optimal basis for the external layer of the suppositories was taken the compound No 10 that consists from cocoa oil and thick licorice extract. The hydrophilic basis for the internal layer, the compound No 1 was used consisting from polyethylenglycol 1,500 and polyethylenoxide 400 in correlation (95:5) due to the acting substance of paracetamol. Double layer suppositories were presented of torpedovisible form, fatty on touching, brown-yellow shade. The surface smooth, homogenous; on the longitudinal incision the presence of the second layer of white cream coloured shade was found.

For the estimation of suppositories quality on the basis of carbonic acid extract of licorice and paracetamol made due to our technology, it was necessary to investigate according to the state pharmacopeia of RK the following findings: external characteristics, disintegration, time of full deformation, $t^{0}$ fusion, homogeneity of mass, homogeneity of the dosage of the acting substances, stability to destruction, microbe contamination, acidic, peroxidic and iodine numbers.

Determination of the reological findings of suppositories with carbonic acid extract of bare licorice and paracetamol.

Structural-mechanical properties of rectal medicinal forms show a considerable influence on their consumer and biopharmaceutical characteristics. They play the main role in choosing the technological parameters, allowing to establish the optimal temperature regimen of preparation and dosage of suppositories mass, speed and time of mixing.

Ticsothropiya of the studied basis was established by the method of continuous, all increasing destruction of the structure, as the function of strain displacement.

The determination was performed according to the regulations of the state pharmacopeia of RK with the use of rotator viscosimeter Visco star plus L. The kinetics of structure-formation in investigated bases was studied in diapason of speed deformation from small to large (0.5-200 rotation/min) and from large to 
small in $\mathrm{t}^{0} 25,40,55$ and $70{ }^{\circ} \mathrm{C}$. During temperature increasing the sample was kept in electric dry aerial thermostat TS-80M during 24 hours.

We investigated the dependence of strain displacement (r) and effective viscosity from the speed gradients of shifted duration (D) in various temperatures for the sample of suppositories with carbonic acid extract of bare licorice and paracetamol, where as the basis was taken polyethylenoxide with the molecular mass 400 and 1500 in correlation 3:2. The diagrams of the average values of tangential stress displacement and dynamic viscidity from gradient of enclosed speed were done, and due to these diagrams judged on duration type system and presence of ticsotropic properties. (Figs. 1 and 2).

The deformation kinetics of suppositories in the region of changing the speed gradients is the evidence that its duration begins not at once, but after some application of stress necessary for the rupture of the structure elements. The investigated sample has nonnewtonian type of duration, its viscidity depends on the stress displacement, the rheogram of duration-nonlinear character. In the period of decreasing stress the viscidity of the system is partially restorated that confirms the presence of plastic-viscid and ticsothropic peculiarities of emulsion.

It is characteristically, that in period of decreasing stress displacement the restoration of the the former structure is behind the schedule. On the rheogram of duration the descending together with the ascending curve form "hysteresis loop" that confirms the ticsothropity of examined suppositories.

In temperature $25^{\circ} \mathrm{C}$ the descending curve is situated from the ascending curve to the left, that points on the destruction of the structure in decreasing the exertion somewhat prevails over its restoration (Fig. 1). The loop width points to the low degree of the structure destruction. The subsequent temperature elevation leads to rather quick structure destruction and decreasing the square area of the hysteresis loop. It is

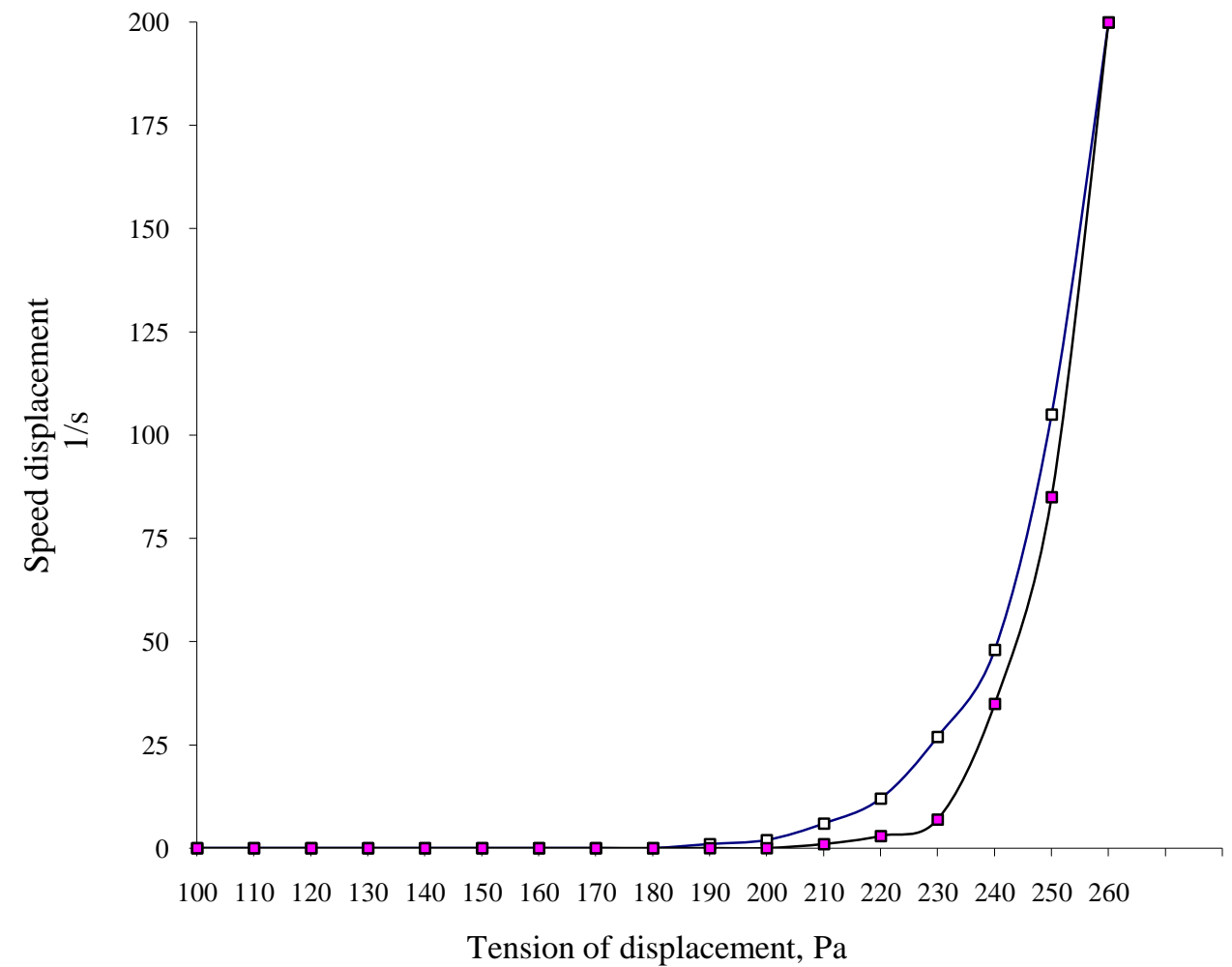

Fig. 1 Rheogram of deformation kinetics of the suppositories sample with licorice extract and paracetamol on the basis of polyethylenoxide in $25^{\circ} \mathrm{C}$. 


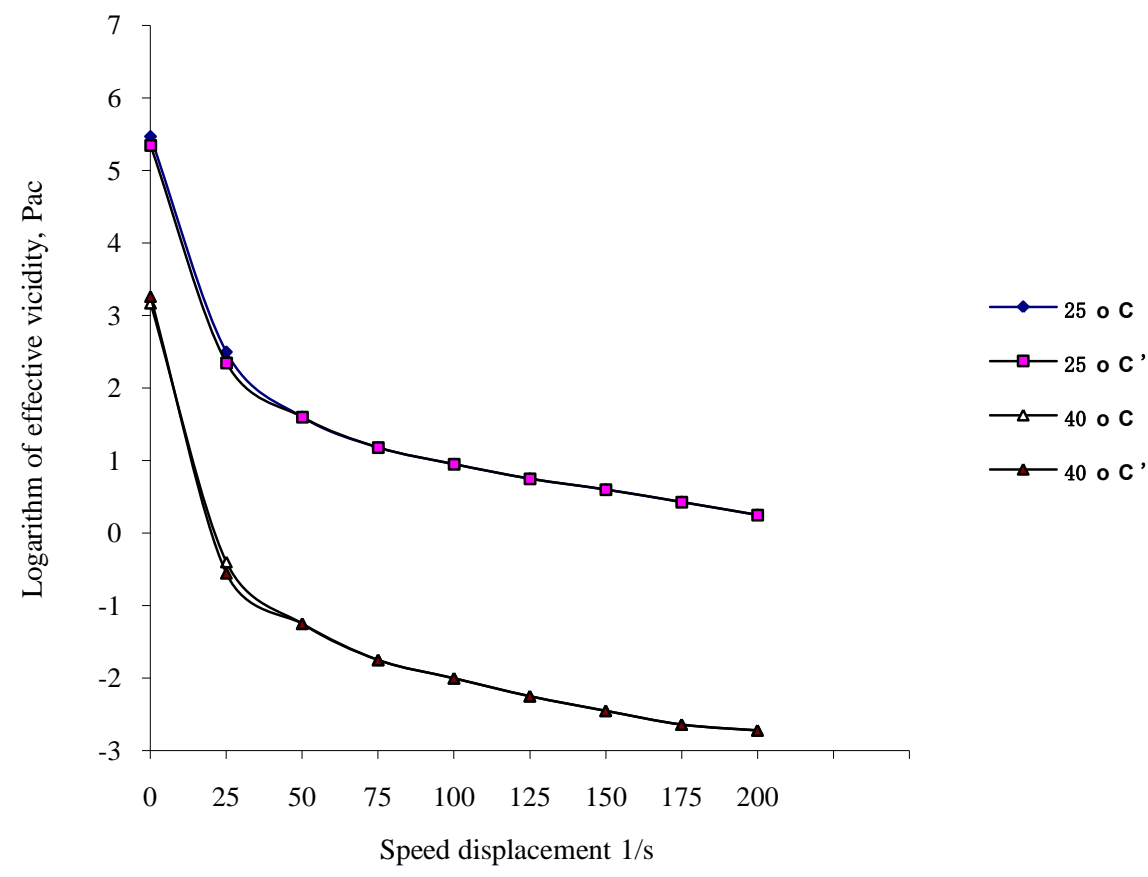

Fig. 2 Dependence of effective viscidity $\left(\right.$ In $\left._{\text {eff }}\right)$ from speed gradient of $D_{r}$ (displacement duration) in varions temperature for the sample of suppositories on polyethylenoxide basis.

obvious that it is connected with the temperature influence contributing to the structure destruction. On degree of structure ointment was judged on the value of MS (mechanical stability). The calculated meaning of mechanical stability for suppositories equal 1.08 points on prevalence in the system of coagylative ties and possible stability in continuous keeping.

As it seen from picture 2 in small speed of displacement the structure of suppositories is destroyed and restorated completely (in this case the system has the greatest viscidity).

In increasing the displacement speed the structure destruction begins to prevail in restoration and the viscidity is reduced.

In large speed the structure displacement is completely destroyed and the system begins to flow. It is known that the structure formation in disperse systems depends on $\mathrm{t}^{\mathrm{o}}$. In temperature increasing from 25 to $55{ }^{0} \mathrm{C}$ the suppositories viscidity on the basis of polyethylenoxide is decreased from 214.9 to 26.4 Pa.c, that is the evidence of great sensitivity of suppositories to the temperature change. Direct or indirect process of gradients speed change varies not enough the viscidity value that says on the absence of strong internal system reconstructions and formation of new phase in temperature diapason from 25 to $55{ }^{0} \mathrm{C}$. However the presence of hysteresis loop shows that in suppositories the marked deformative regulation is occurred.

On Fig. 3 the character changes of dynamic viscidity with the temperature increasing for the tested suppository is presented.

The heating of the basis leads to the reduction of its structural viscidity and consequently to the loss of tiscothropity.

As it seen from Fig. 3 the logarithm of effective suppositories viscidity, the indirect dependence from temperature is discovered. The more lower the temperature the more quicker and deeper are the processes of structure formation. The studied basis gives a sharp elevation of maximum displacement stress with the reducing of temperature. This property of suggested basis has the great practical value.

On Fig. 4 the dependence of effective viscidity of suppositories from indirect temperature is given. 


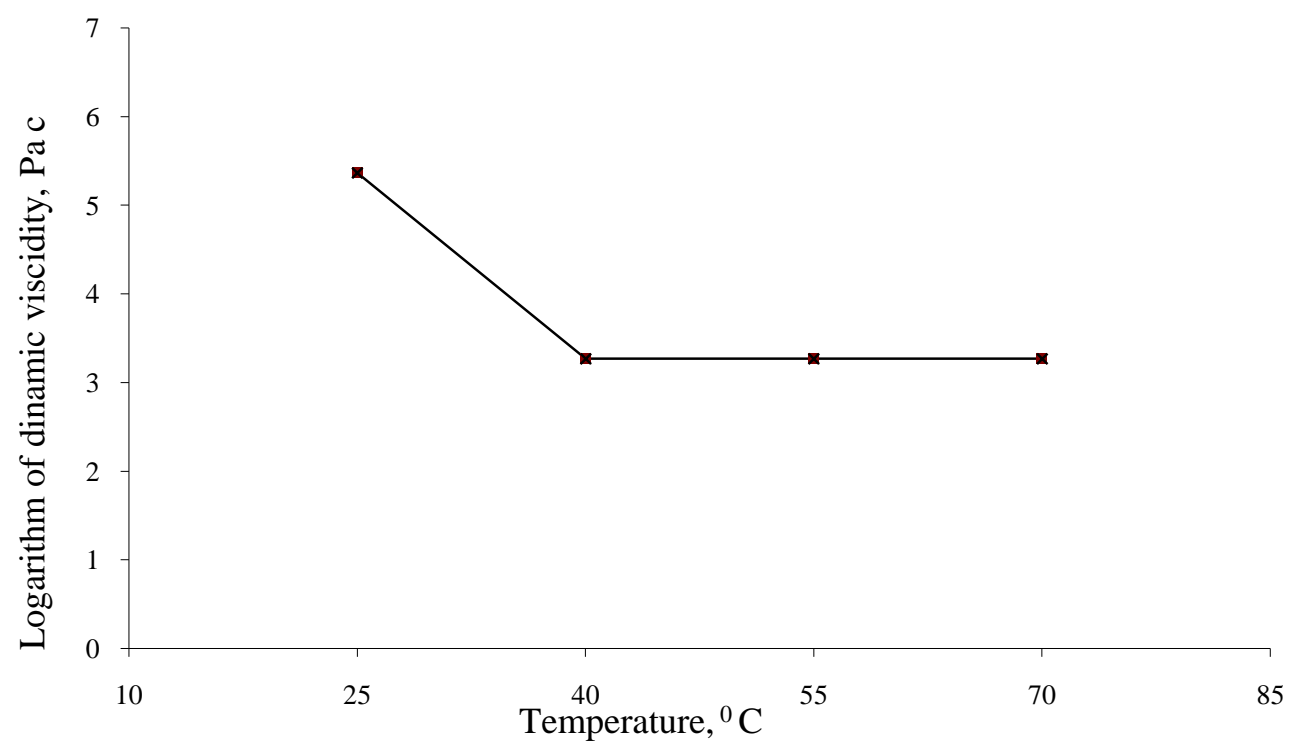

Fig. 3 The decrease of dynamic viscidity $\left(\mathrm{In \eta}_{\mathrm{eff}}\right)$ with the temperature increase $(\mathrm{T})$ of suppositories on the basis of polyethylenoxide and cocoa oil as it seen from the diagram the temperature elevation leads to the change of suppositories fluidity. The principal difference in the course of curves in elevating and reducing the speed displacement duration of the investigated sample is not observed.

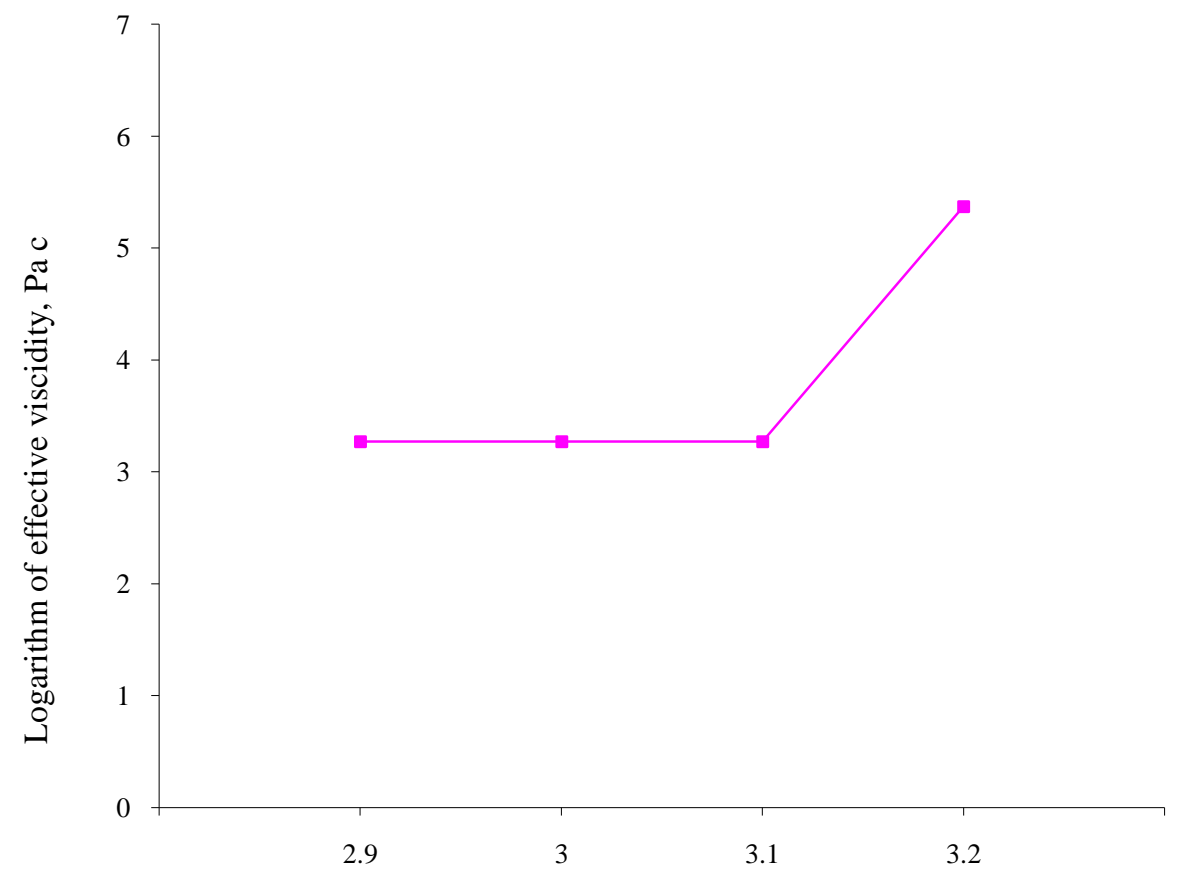

Indirect $\mathrm{t}^{0}, 1 / 1000 \mathrm{~T}, \mathrm{~K}$

Fig. 4 The dependence of effective viscidity $\left(\mathrm{In \eta}_{\text {eff }}\right)$ from indirect temperature $\left(1 / 10^{3} \mathrm{~T}\right)$ of suppositories on the basis of polyethylenoxide and cocoa oil.

From the performed investigations we can do the conclusion that suppository basis received on the basis of polyethylenoxides possesses the clearly marked ticsothropity and small meanings of limited 
displacement stress and plastic viscidity in various temperatures. It means that the basis structure is easily destroyed, but quickly restorated, if the basis stays at rest, that has the essential significance in keeping the suppositories on this basis. Thus, as the result of performed investigation the following compound of suppositories with carbon acid extract of licorice and paracetamol was worked out.

The hydrophobic basis for the external layer of double layer suppositories is composed of carbon acid extract of bare licorice -0.2 gr. and cocoa oil in quantity $4.0 \mathrm{gr}$.

The hydrophilic basis for the internal layer was the composition consisting of polyethylenoxide 1,500 and polyethylenoxide 400 at ration (95:5) of the acting paracetamol substance.

The following stage of the work was the determination of speed and the fullness of releasing of the acting substances from suppositories by the method "in vitro".

For the determination of speed and fullness of releasing of the acting substance from the suppository form on the basis of licorice and paracetamol the method of balanced dialysis through semipermeable membrane due to the method of L. Kruvchinsky was used (Fig. 5).

The determination was performed at temperature 40 $\pm 2{ }^{\circ} \mathrm{C}$ on the hydrophilic basis. As the semi- permeable membrane the cellophane with thickness $49 \mathrm{mkm}$ was used. The area of dialysis surface is $9 \mathrm{sm}^{2}$. The model medium for performing of dialysis serves the distilled water.

In $15,30,45,60,120,240$ minutes from the beginning of dialysis the samples were selected and determined in dialysates the content paracetamol and glyderinin by the method of gas liquid chromatography analysis, the initial column temperature $-35{ }^{\circ} \mathrm{C}$ with further elevation to $270{ }^{\circ} \mathrm{C}$ with speed $2{ }^{\circ} \mathrm{C}$ in min.

It was established by the investigation that full and intensive releasing of the active substances from the medicinal form is occurred to 45 minute of releasing dialysis and was $78.2 \%$.

The results of the work: The outward appearance. All series of the medicinal preparations with carbon acid extract of bare licorice are presented as suppositories of torpedotype form, fat to the touching, light-brown color, surface- smooth, homogenous; on the longitudinal incision in separate samples small aerial cavities were found.

The disintegration of all series of preparation was within the limits 13-15 minutes that corresponds to the requirements of state pharmacopeia RK.

The time of full deformation was 13, 3-14, 6minutes for the received suppositories that satisfy the requirements of state pharmacopeia RK.

Temperatures of fusion of suppositories selected from

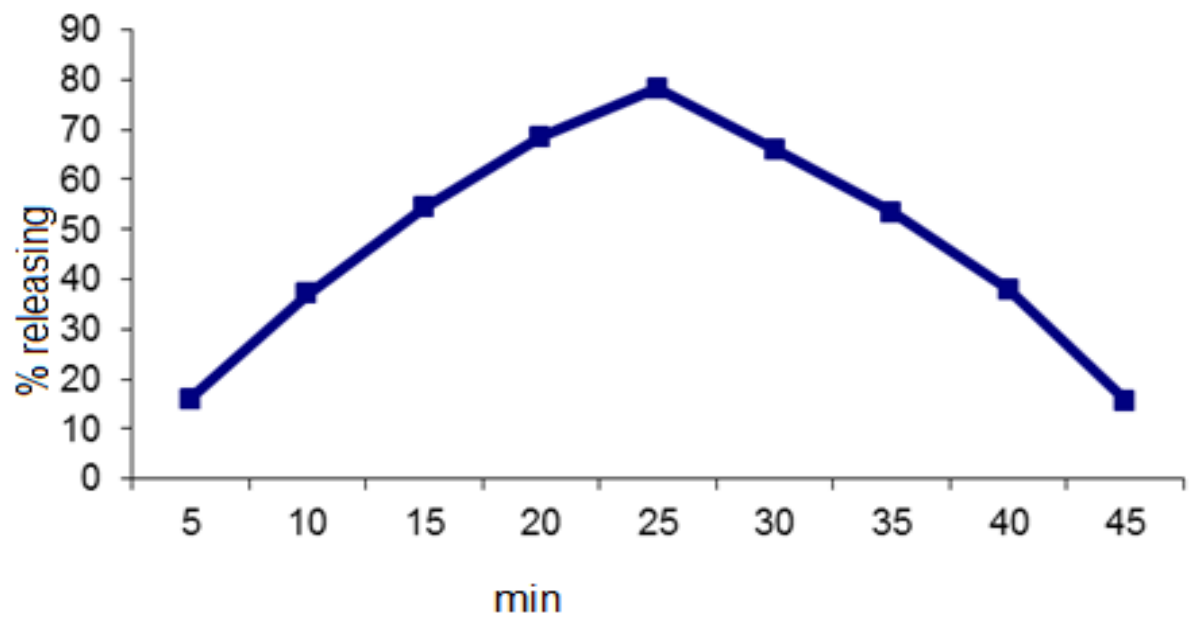

Fig. 5 Determination of speed and fullness releasing of the acting substance from suppositories on the basis of licorice and paracetamol. 
Basis of Licorice Extract and Paracetamol

Table 1 Findings of suppositories quality with carbon acid extract of bare licorice and paracetamol.

\begin{tabular}{|c|c|c|c|c|c|}
\hline \multirow{2}{*}{ Findings } & \multirow{2}{*}{ Permissible norms } & \multicolumn{4}{|c|}{ Meaning of the finding on series } \\
\hline & & 011014 & 021014 & 031014 & 041014 \\
\hline Outward appearance & - & \multicolumn{4}{|c|}{ Corresponds to description } \\
\hline Disintegration, $\min$ & $\leq 30 \mathrm{~min}$ & $13.1 \pm 0.49$ & $15.3 \pm 0.28$ & $16.1 \pm 0.29$ & $14.0 \pm 0.33$ \\
\hline Time of full deformation, min & $\begin{array}{l}\text { not more than } 15 \\
\text { min }\end{array}$ & $14.2 \pm 0.28$ & $13.3 \pm 0.25$ & $14.6 \pm 0.15$ & $13.4 \pm 0.28$ \\
\hline Temperature melting, ${ }^{0} \mathrm{C}$ & $\leq 37{ }^{0} \mathrm{C}$ & $36.7 \pm 0.09$ & $36.1 \pm 0.08$ & $35.8 \pm 0.14$ & $35.7 \pm 0.21$ \\
\hline Average mass, gr. & $3,8-4,2 \mathrm{gr}$ & 3,7979 & 3,7940 & 3,9594 & 4,0614 \\
\hline Deviation from average mass, $\%$ & $\pm 5 \%$ & $+2,79 \%$ & $-4,61 \%$ & $-3,17 \%$ & $-3,20 \%$ \\
\hline Stability to destruction, gr. & $\geq 1600$ gr. & $3100 \pm 32$ & $3120 \pm 37$ & $3210 \pm 37$ & $3060 \pm 37$ \\
\hline Acidic number & not more 1,0 & $0.55 \pm 0.02$ & $0.57 \pm 0.02$ & $0.49 \pm 0.02$ & $0.56 \pm 0.03$ \\
\hline Peroxide number & not more 3,0 & $0.05 \pm 0.00$ & $0.06 \pm 0.01$ & $0.04 \pm 0.01$ & $0.05 \pm 0.01$ \\
\hline Iodine number & not less 6,0 & $11.50 \pm 0.12$ & $9.60 \pm 0.12$ & $10.47 \pm 0.05$ & $10.40 \pm 0.06$ \\
\hline $\begin{array}{l}\text { Microbiological contamination: } \\
\text {-bacteria + fungi, KOE/gr. (colony } \\
\text { forming unites) }\end{array}$ & $10^{2}$ & 40 & 50 & 30 & 35 \\
\hline -Enterobacteriaceae & not allowed & absent & absent & absent & absent \\
\hline
\end{tabular}

varions series were within the limits of $35.7-36.8{ }^{0} \mathrm{C}$ that are not exceed the normal temperature in the rectum.

The results of investigation due to the findings of suppositories quality with carbon acid extract of bare licorice and paracetamol is presented in Table 1.

The average mass of suppositories with carbon acid extract of bare licorice was 3,7979-4,0614 gr. The maximal deviations from the average mass in sample of preparation varied from -4.61 to $2.79 \%$. Thus, all the investigated series satisfied the requirements state pharmacopeia of RK.

The trials of suppositories stability to destruction (EP5, p2.9.24) showed that the analyzed preparation stand the exertion 3-3.2 kg. This is the evidence of sufficient mechanical firmness of suppositories and this firmness due to the experiment must be not less $1.6 \mathrm{~kg}$.

\section{Conclusions}

Thus, it was for the first time when the performed tests on selection for the optimal compound, the development technology of producing double layer suppositories of combined action, determination of reological findings and standardization of suppositories on the basis of licorice extract and paracetamol were perfofmed.

\section{References}

[1] Obolentseva, G. B., Litvinenko, B. I., Ammosov, A. S. et al. 1999. "Pharmacological and Therapeutic Properties of Licorice Preparation.” Chem. Pharm. Journal 8: 24-31.

[2] Pavlova, S. I., Uteshev, B. S., and Sergeev, A. V. 2003. "Licorice. Possible Mechanisms of Antitoxic Anticarcinogenous and Antitumor Properties." Chem. Pharm. Journal 37 (6): 36-9.

[3] Baltina, L. A. Davydov, V. A. and Vasiliev, E. V. 1996. "Anti-inflammatory Properties of Licorice Preparations." Chem. Farm. Journal 8: 4-16.

[4] Ushbaeva, G. G. Kabieva, S. A. Vermenich S. M. et al. 2000. "Licorice Chemo Modifying Source of Funds for the Treatment of Tumors." In Cancer Problem of the XXI Century. Almaty, 401-4.

[5] Starokozhko, L. E. 1996. "Research and Immunomodulatory Properties of the Membrane-Preparations of Licorice Roots." Journal of Dermatology and Venereology 4: 22-5.

[6] Muravyev, I. A., Starokoshko, L. Ye., Kolesnikov, O. P. et al. 1992. "The Study of Immunomodule Properties of Glycyram and Dense Extract of Liquorice Root." Chem. Pharm. Journal 9-10: 39-49.

[7] Stepanova, E. F., and Sampiev, A. M. 1997. "Investigation Condition and Prospects of Using Bare Licorice Herb." Chem Pharm. Journal 31 (10): 39-43.

[8] Egorov, M. V., Kurkin, V. A., Zapesochnaya, G. G. et al. 2005. "Validation of Method of Qualitative Analysis of Raw Materials and Licorice Preparations." Pharmacy 53 (1): 9-12. 